\title{
Structural Analysis with Knowledge-based MICMAC Approach
}

\author{
Ahmed Omran \\ Computer Science \\ Department. Faculty of \\ Computers and Information, \\ Fayoum University
}

\author{
Motaz Khorish \\ Decision Support Department. \\ Faculty of Computers and \\ Information, \\ Cairo University
}

\author{
Mohamed Saleh \\ Decision Support Department. \\ Faculty of Computers and \\ Information, \\ Cairo University
}

\begin{abstract}
In long term view, policy/decision makers need to justifiable anticipation for the major future drivers that may effect on their domain key variables. In this paper, we develop a knowledge-based structural analysis approach that based on integrating of RT-Delphi, structural analysis, knowledgebased and explanation modeling capabilities. We applied the developed approach in two crucial domains in Egypt, which are food security and water security (milk production). In addition, it was 15 and 25 experts participate in food security and water security cases. They share knowledge for identifying, analyzing and foreseeing potentials of Egypt's water and food security as ground to thinking of pilot solutions aimed at evading problems and futures drivers as well as developing a repository of knowledge whereby Egypt's policy/decision makers are attained.
\end{abstract}

\section{General Terms}

Intelligent Decision support system and structural analysis.

\section{Keywords}

Intelligent Decision support system, Structural analysis, MICMAC approach, RT-Delphi, Ontology KB and explanation.

\section{INTRODUCTION}

Structural analysis represents a powerful and well designed tool for knowledge sharing and experiences transfer. It provides stimulating reflection within the domain experts group, and it can be easily applied to problems formulated in a matrix design and it supports the qualitative studies [1]. It provides for studying the relations, to identify the influential and dependency domain drivers. Also, there are different advantages of traditional structural analysis that are: enabling a group to find a method to share ideas among group members and it provides domain participants to make their views and thinking about a specific problem $[1,2]$.

The traditional structural analysis has different limitations, which are: the subjectivity for listing the target items, representing a long process and not efficient for time, cost and human resources. Also, it don't provides the multi participatory approach, thus, it limited with a small group of experts (not more than 12). In addition, its result may be strongly biased. Finally, it not provides the imagination and innovation $[3,4,5]$.

Arcade and Godet contribute the structural analysis with MICMAC (Impact Matrix Cross-Reference Multiplication Applied to a Classification) that represents a structural analysis based on comparing the hierarchy of issues in the various classifications (direct, indirect and potential), which is a rich source of information to determine the major wildcards of a specific domain [5].

The Delphi method is a powerful and a well structured tool for knowledge acquisition, because its anonymity process. In Delphi method the process for knowledge acquisition from domain participators is done by controlled opinion feedback for a series of questionnaires. It provides the domain participators to move toward consensus [6]. Moreover, RTDelphi is a round-less Delphi applied as an on-line tool. Also, it is widely used to improve the efficiency of knowledge acquisition process from the domain experts and to create a large participatory and anonymity on-line system with between all participants (system analysts, researcher, experts, and decision/policy makers) $[7,8]$.

The domain ontology is crucial in order to harmonize the meaning of concepts and provide richer relationships between them. This paves the way towards the knowledge acquisition process by minimizing the chances of misunderstandings when debating a certain concept or a problem [9]. It provides for reducing the contradiction of the experts' judgments by defining a common language between domain experts and avoiding misunderstandings when talking about specific topics. Ontology describes domain concepts and their attributes and all relationships that hold between these concepts [10]. The explanation facilities for the knowledgebased model indeed influence policy/decision maker confidence in acceptance the consensus results [11].

An important research frontier, which we address in this paper, is to develop a novel structural analysis (SA) approach that provides the efficiency and effectiveness of identifying the influential and dependency drivers of a specific domain. Also, provides explanation capabilities for the SA consensus results.

\section{PROBLEM ADDRESSED}

In long term view, policy/decision makers need to identify the future influential and dependency drivers for a specific domain. Classical structural analysis, as futures analysis widely used method, always depends in a small group of participators, not efficient for time, cost and human resources, single value-based. In addition, its result may be strongly biased. Finally, it not provides the imagination and innovation, which are crucial for long view.

\section{SOLUTION PROPOSED}

\subsection{The Developed Framework}

As shown in figure.1, the developed framework consists of three main sub-systems, which are model-based, knowledgebased and graphical user interface sub-systems. 


\subsubsection{Model-based subsystem}

It consists of two components, which are: model base and model-base management systems (MBMS). The model base consists of two models, which are MICMAC and the enhanced web-based RT-Delphi. In addition, the MBMS provides integration, execution, and graphical interface capabilities. The graphical interface model provides the integration among mathematical models, knowledge and different databases.

\subsubsection{Knowledge-based subsystem}

It consists of two components, which are: knowledge-base and knowledge-based management system. The knowledge based management system provides knowledge acquisition, retrieving, saving and communication capabilities between all other sub-systems. The Knowledge-base consists of three models, ontology KB, "Why" and "What if" explanation models. The ontology KB model consists of six subanthologies: model drivers, model variables, participators, questionnaires, planning bedrock, policy, which are consist of different concepts. Each sub-ontology consists of different concepts' prosperities (name, description, weight ranking and its impact). The explanation sub-component consists of "What if" and "Why" analysis. "What if" analysis is used for generating and evaluating alternative scenarios that can reduce the uncertainties associated with the long-term. Also, the "Why" analysis increases the confidence of policy/decision makers about the consensus results. Final, the domain expert knowledge consists of two main categories, which are experts' judgment and its justifications. Expert justifications of their judgment are the core of "Why" analysis.

\subsubsection{Web-based user interface, visualization and report generation sub-system}

A report generation, visualization and justification sub-system provide the policy/decision decision maker capabilities for reporting consensus summary information, consensus justifications and the visualization capabilities. Explanation or justification capabilities give faith more in results, more confidence in the system, and to present the different assumptions underlying the system explicitly.

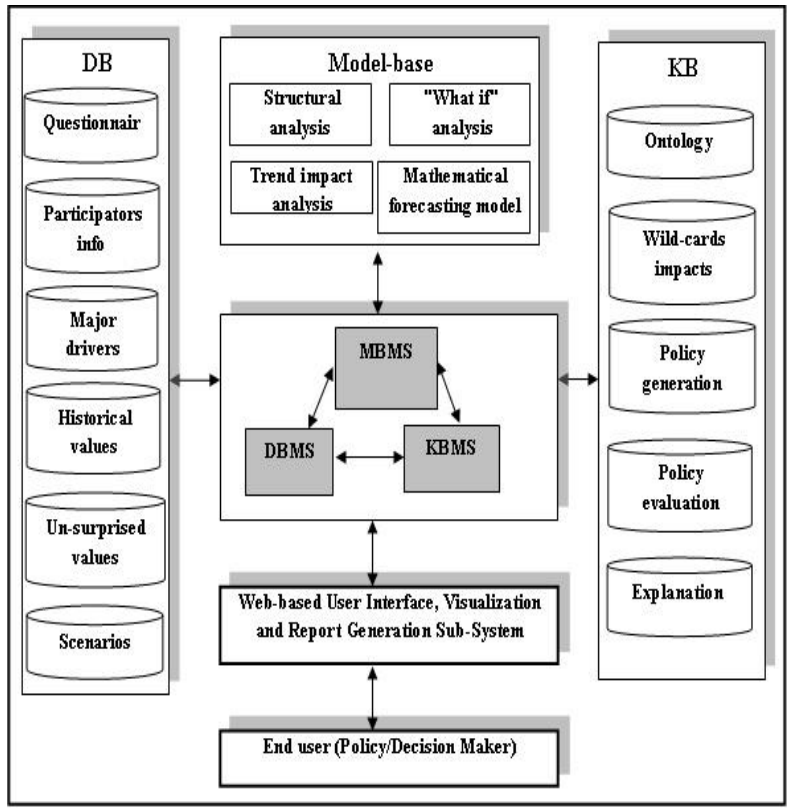

Fig1.'conceptual view of the developed framework'

\subsection{Inputs and Outputs}

The inputs of the knowledge-based structural analysis approach are based on the knowledge of nominated and weighted experts. Table1 lists the inputs used in the developed new approach (the usage of each input will be illustrated in the algorithm section). As shown in table 2, the two major outputs of are: the KB-MICMAC Matrix, and "Why" and "What if". Also, based on the KB-MICMAC Matrices, policy/decision makers can determine the influential and dependency drivers with the domain experts' explanation.

Table 1. Inputs of the developed new approach

\begin{tabular}{|c|c|c|}
\hline $\begin{array}{c}\text { Short } \\
\text { Name }\end{array}$ & Full Name & Type \\
\hline MICMx & $\begin{array}{c}\text { Structural analysis based on } \\
\text { MICMAC Matrix }\end{array}$ & 2D-Matrix \\
\hline
\end{tabular}

Table 2. Outputs of the developed new approach

\begin{tabular}{|c|c|c|}
\hline $\begin{array}{c}\text { Short } \\
\text { Name }\end{array}$ & Full Name & Type \\
\hline DrMx & Drivers Types Matrix & 1D-Matrix \\
\hline
\end{tabular}

\subsection{The Developed Methodology}

Below, we shall explain the developed methodology. The developed methodology is based integrating five futures studies and knowledge-based methods, which are the structural analysis, based on MICMAC and the web-based RT-Delphi, ontology KB, "What if" and "Why" analysis methods.

Experts' knowledge is elicited using MICMAC RT-Delphi matrix. In knowledge acquisition process, there are two types of information represented in matrix form. The first type is the guide-information that contains 4 items for each item of the web-based MICMAC RT-Delphi questionnaire: (1) median response of the expert group (2) the number of responses made (3) justifications that the other experts have given for their responses, which are being ordered by values. On the other hand, the second type is the judgment information that allows the experts to add a new numerical answer and type his/her justifications for their own answer(s). A group of the domain experts can fill in the structural analysis matrix over a period of time determined by the domain analysts, in the questionnaire's design step. When the relationship is direct influence, the filling-in direct influence is low (1), medium (2) or high (3). In addition, zero value (0), appears if there is not a relation. After the final matrix is normalized, summation process for both rows and columns are applied. Figure 2 shows the flowchart of the web-based MICMAC RT-Delphi. 


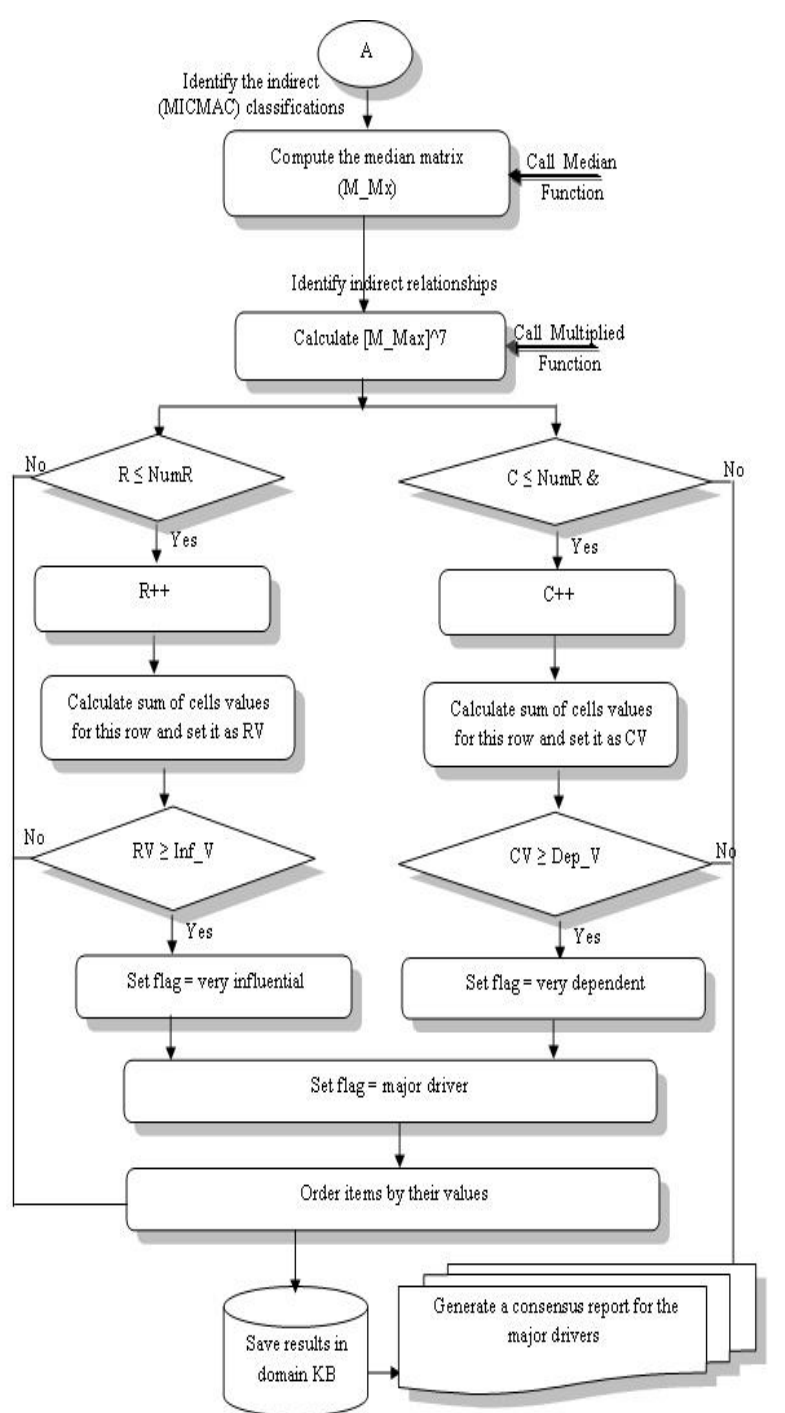

Fig2. Web based MICMAC RT-Delphi flowchart

In addition, "Why" and "What if" explanations about the consensus result provide practice that is required for the system policy/decision makers. This can reduce the uncertainties associated with experts' judgments. In addition, by using "What if" explanation, the evaluation of different external drivers and their relations can be provided. Policy/decision can easy change the value in the consensus matrix and run the system again to measure the impact of this change. This can provide to reduce the uncertainties associated with the long-term strategic decision.

Moreover, based on "Why" explanation, policy/decision makers will be more confident about the consensus results. Each value from the output matrix associated with a specific Meta knowledge to justify "Why" the domain expert fill this value. Figure 3 and Figure4 show the flowchart of both "What if" and "Why" explanation. Moreover, the developed methodology enhances the current RT-Delphi by integrating a formal ontology in order to harmonize the meaning of concepts and provide richer relation between them. This paves the way towards the knowledge acquisition process by minimizing the chances of misunderstandings when debating a certain concept or a problem. It provides for reducing the contradiction of the experts' judgments. Figure 5 shows the architecture of the ontology KB. Also, ontology KB Model provides to build a knowledge repository for a specific domain. It consists of three main parts, which are ontology knowledge base (ontology KB), ontology building editor and editor GUI. The developed ontology architecture represents its concepts and the relationship between them.

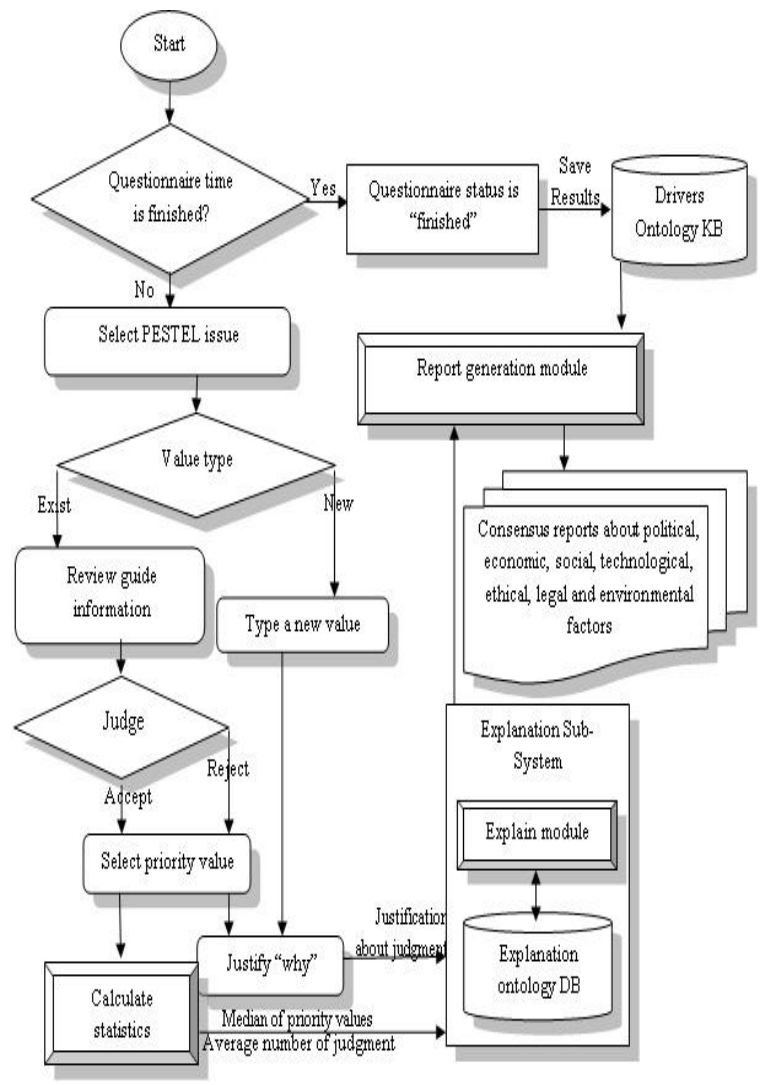

Fig3. "Why" explanation flowchart

\subsection{The Developed Tool}

The developed tool is used to make information and knowledge manipulation more efficient in data gathering, as well as provide enhanced group memory for alternative generation and evaluation. It provides the capabilities of defining domain participators, their roles, weights and communications. Also, it creates a large-scale asynchronous or synchronous participation network. As shown in figure6, the two major components of the developed tool are the backend and front-end components. The Back-end component provides data security and management functionality that enable the defined domain analysts to build and manage his/here ontology and questionnaires. But the front-end component provides knowledge acquisition, output presentation and explanation capabilities.

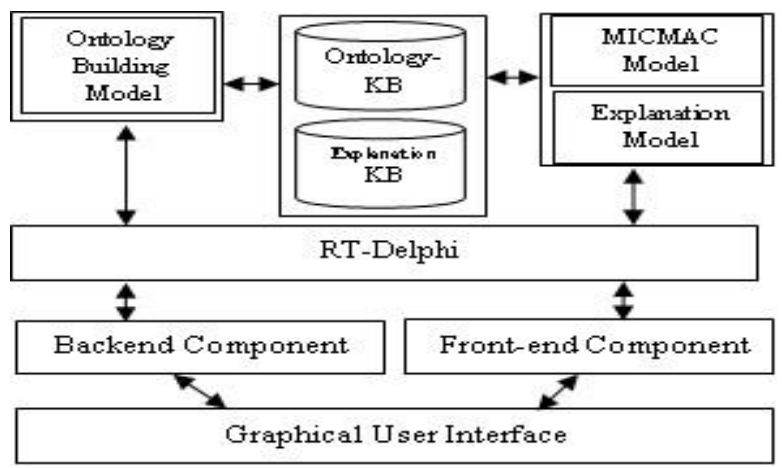

Fig6.The Developed Tool Components 


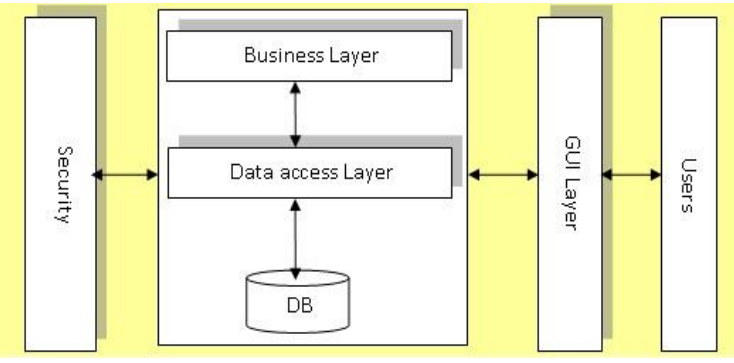

Fig7.The Developed Tool Architecture

As shown in figure.7, there are three main layers in the developed tool, which are: the data access layer (DAL), the business layer and the presentation layer. These layers provide security, communication and managing all system's operations. The data access layer (DAL) provides simplified access to data stored in the system database. The business layer describes the functional algorithms, which handle information's exchange between a data access layer and a user interface. Finally, the presentation layer represents the design of the user interface pages. The developed tool phases are build a formal ontology, design domain questionnaires, knowledge acquisition, scenarios generation, visualization and report generation phases.

\section{CASE STUDY}

The following examples illustrate the use and implementation of the new approach:

\section{- The Egyptian Milk Production}

The objective in this case-study is to help the policy/decision makers, in the Egyptian ministry of agriculture, to improve the quality of their long-term strategies from 2013 to 2030 to reduce the milk production gap (the difference between the national consumption and production) [12].We applying the web-based RT-Delphi MICMAC to identify the major future drivers.

In this case, the number of the domain experts is fifteen. Also, eleven futures drivers are suggested from the domain experts. First, drivers are listed in web-based RT-Delphi MICMAC. As shown in Table.3, the consensus results of the structural analysis show that the World financial crises (E1), The Dissemination of the Epidemic diseases (E2) and Bad weather conditions (E3) are the key drivers for the future of the Egyptian milk production.

\section{- The Egypt's Water Security}

In Egypt, water security tops the national agenda whereby studies reveal that estimations of available water and water needs for different purposes are heading towards an increasing gap between water supply and demand. Water gap, in Egypt, is likely to increase by time, not only because of the anticipated increase of water demand, but also due to the impact of other factors on the available quantity of Nile water $[13,14]$.

Based on the consensus results of 25 domain experts about the issue of Egypt's water security, the most important drivers affecting Egypt's water security were identified as follows:

A. The trend of relations between countries of the Nile basin towards either cooperation or struggle.

B. Impact of external powers stimulating conflicts or cooperation.

C. Shifting of some Nile basin countries to irrigated agriculture and minimizing pressure on the blue water.
D. The nature of change in the economic conditions in countries of the Nile basin.

E. Some of the Nile basin countries constructed water reservoirs or control utilities.

F. High impact of climate change on the water yield of the Nile basin.

G. The impact of the separation of South Sudan on the Egyptian water yield from the Nile basin.

H. Political stability or instability in domestic policy of the Nile basin countries.

Table.3. Case1.WRT-MICMAC Consensus Results

\begin{tabular}{|l|l|}
\hline Diver Name & Type \\
\hline Global temperature & Low Influence, Low Dependent \\
\hline New animal disease & Low Influence, Low Dependent \\
\hline Global economic goes up & High Influence, Low Dependent \\
\hline World financial crises & Key wildcard event \\
\hline Economical instability & Low Influence, Low Dependent \\
\hline $\begin{array}{l}\text { Dissemination of the } \\
\text { Epidemic diseases }\end{array}$ & Key wildcard event \\
\hline Major road accidents & Low Influence, Low Dependent \\
\hline Major natural wildcards & Low Influence, Low Dependent \\
\hline $\begin{array}{l}\text { Significant pollution } \\
\text { increasing }\end{array}$ & Low Influence, Low Dependent \\
\hline Bad weather conditions & $\underline{\text { Key wildcard event }}$ \\
\hline Elimate change in the & Low Influence, Low Dependent \\
\hline
\end{tabular}

Table.4. Case2.WRT-MICMAC2 Consensus Results

\begin{tabular}{|l|l|}
\hline $\begin{array}{l}\text { Diver } \\
\text { Name }\end{array}$ & Type \\
\hline A & $\underline{\text { Key wildcard event }}$ \\
\hline B & $\underline{\text { Key wildcard event }}$ \\
\hline C & $\underline{\text { Key wildcard event }}$ \\
\hline D & High Influence, low Dependent \\
\hline E & High Influence, Low Dependent \\
\hline F & Low Influence, Low Dependent \\
\hline G & Low Influence, Low Dependent \\
\hline H & Low Influence, Low Dependent \\
\hline
\end{tabular}

\section{CONCLUDING REMARKS AND}

\section{FUTURE WORK}

Policy/decision makers need justifiable estimates for the major influence drivers that may effect on their domain key variables. We can summarize, in this paper, we develop a knowledge-based structural analysis approach. The developed approach is based on integrating of RT-Delphi, MICMAC, knowledge-based and explanation modeling capabilities. We applied the developed approach in two crucial domains in Egypt, which are food security and water security (milk production). In addition, it was 15 and 25 experts participate 
in food security and water security cases. They share knowledge for identifying, analyzing and foreseeing potentials of Egypt's water and food security as ground to thinking of pilot solutions aimed at evading problems and futures drivers as well as developing a repository of knowledge whereby Egypt's policy/decision makers are attained. Table 5 represents a summary about the main difference between both classical approach and the developed one. The developed framework improves the quality of long-term strategic decision. It transforms the process of developing a strategic decision from a one-man's show into a large scale asynchronous or synchronous participation process. Also, it provides the distributed interaction capabilities and helps in building and managing knowledge repositories for decision making process. This is a very important aspect in developing long-term strategy, thus, it is better to have as much experiences and future imagination to reduce both real complexity and uncertainty.

To evaluate the developed framework efficiency (time and money cost), we applied the traditional approaches of knowledge acquisition and analysis (hardcopy questionnaire and workshops) in parallel with using the developed framework with the same participators and conditions (money payment). The results conclude that the developed framework save money (preparing workshops, conferences, knowledge acquisition meetings and experts' transportation cost) by almost $45 \%$ and time (questionnaire designing, knowledge acquisition, expert inviting, result analysis and availability of the consensus results) by 45 to $50 \%$. The following table discuses.

Table.5. Classical versus the developed approach

\begin{tabular}{|l|l|l|}
\hline Items & $\begin{array}{l}\text { Classical } \\
\text { structural } \\
\text { approach }\end{array}$ & $\begin{array}{l}\text { The developed } \\
\text { approach }\end{array}$ \\
\hline $\begin{array}{l}\text { Provides participatory } \\
\text { approach for analysis }\end{array}$ & Yes & No \\
\hline Number of experts & Limited & No limitation \\
\hline Efficiency & More & less \\
\hline Effectiveness & More & less \\
\hline Single/Multiple view & Multiple & single \\
\hline $\begin{array}{l}\text { Explanation } \\
\text { Not provided }\end{array}$ & $\begin{array}{l}\text { "Why" and "What } \\
\text { if" Explanation }\end{array}$ \\
\hline $\begin{array}{l}\text { Knowledge } \\
\text { acquisition } \\
\text { methodology }\end{array}$ & $\begin{array}{l}\text { Hard document } \\
\text { questionnaires }\end{array}$ & $\begin{array}{l}\text { Web-based RT- } \\
\text { Delphi }\end{array}$ \\
\hline
\end{tabular}

The next step in the developed research is to apply policy generation and evaluation approach to create policies that can help policy/decision makers to manage the future threats. Also, data-mining techniques can be used as a powerful tool for automated ontology building.

\section{REFERENCES}

[1] Glenn, J., Gordon, T. 2003. "Futures Research Methodology V2", CD ROM, the Millennium Project, American Council for the United Nations University.
[2] Gordon, T., Glenn, J., Jakil, A., 2005. "Frontiers of futures research: What's next?",Technological Forecasting and Social Change, Volume 72.

[3] Gordon, T., 2003.The Delphi method, "Futures Research Methodology V2", CD ROM, the Millennium Project, American Council for the United Nations University.

[4] Gordon, T., and Glenn, J., 2003.Environmental Scanning., "Futures Research Methodology V2", CD ROM, the Millennium Project, American Council for the United Nations University.

[5] Arcade, J., Godet, M., Meunier, F., Roubelat, F., 2003.Structral Analysis, "Structural analysis with the MICMAC method \& Actors' strategy with MACTOR method", CD ROM, the Millennium Project, Laboratory for Investigation in Prospective and Strategy (LIPS).

[6] Christoph, M., Arkow, D., Heiko, G.2013. "A Delphibased risk analysis-Identifying and assessing future challenges for supply chain security in a multi-stakeholder environment", Technological Forecasting and Social Change Journal, V 80, pp 1815-1833, Science Direct, Elsevier, 2013.

[7] Gordon, T., and Pease, A., 2006. "RT-Delphi: An Efficient, "Round-less" Almost Real Time Delphi Method", Technological Forecasting and Social Change, Volume 73, Issue 4.

[8] Omran, A., Agami, N., Saleh, M., El-Shishiny, H., 2008. "Integration strategic planning and futures studies: theoretical justifications", INFOS.

[9] Eriksson, H., 2003. "Survey of knowledge acquisition techniques and tools and their relationship to software engineering", the journal of systems and software, pp.97107.

[10] Omran A., M.Saleh , H.El-Shishiny “An Intelligent DSS to Anticipate the Impacts of Wildcards on the Tourism Industry in Egypt", The International Conference on Intelligent Systems Design and Applications (ISDA), 2010.

[11] Peter, S., Kristian, B., Ted, F., 2013 "Future scenarios to inspire innovation", Technological Forecasting and Social Change Journal, V.80, pp 432-443, Elsevier.

[12] Omran, A., Saleh, M., Khorshid, M., 2010.“A Decision Support System for the Egyptian Food Security", The International Conference on Intelligent Systems Design and Applications.

[13] AbdulWahhab, A., 2009. "River Nile Basin: Cooperation opportunities and problems", Cairo, Al Ahram Center for Political and Strategic Studies.

[14] Taye, M., 2007. "Water Security in the Arab Gulf in a Changing World: between Prerequisites of National Interest and Addressing External Threats", Middle East papers, National Centre for Middle East Studies, Vol. 38. 